\title{
Higher education and non-pecuniary returns in Germany: Tracing the mechanisms behind field of study effects at career start
}

\author{
Markus Klein \\ Mannheim Centre for European Social Research (MZES), University of Mannheim
}

\begin{abstract}
The paper addresses the question why fields of study differ in early labour market returns in Germany. From a supply-side perspective, it is argued that the higher the potential training costs of a field of study the lower the signalling value in the labour market. The amount of training costs is determined by occupational specificity and selectivity of the studies. As to demand-side considerations, the paper suggests that institutionalized linkages between fields of study and occupations act as mediators for differences in non-pecuniary returns. Both supply-side and demand-side mechanisms substantially contribute to the explanation of field of study differences. The disadvantages of 'soft fields' can be attributed to less occupationspecific and less selective study programmes as well as weaker access to privileged positions in the civil service.
\end{abstract}

Keywords:

Field of Study, Labour Market Outcomes, Occupations, Mechanisms, Germany 


\section{Introduction}

In recent years social scientists have been increasingly concerned with the labour market rewards of fields of study. Several authors argue that during educational expansion the field of study becomes a more significant selection criterion for the allocation of individuals into jobs (van de Werfhorst 2002; Hansen 2001). As a result of a decreasing variance in educational attainment higher education tends to provide a less reliable signal (Jackson, Goldthorpe, and Mills 2005; Kim and Kim 2003).Thus, employers increasingly rely on other potential productivity traits such as horizontal differentiations. Besides, the signalling value of 'soft fields' (Biglan 1973), such as humanities or social sciences, may have become less distinctive due to a more heterogeneous graduate population in terms of abilities (Reimer, Noelke, and Kucel 2008).

Most studies that try to explain the gender wage gap by considering the field of study as a control variable (Loury 1997; Daymont and Andrisani 1984; Kalmijn and Van der Lippe 1997; Gerhart 1990; Marini and Fan 1997; Bobbitt-Zeher 2007). In recent years, the literature also focuses on field of study differences in occupational prestige (Katz-Gerro and Yaish 2003; Shwed and Shavit 2006), access to service class positions (Kim and Kim 2003), employment status (Reimer and Steinmetz 2009; Smyth 2005), job mismatches (Robst 2007; Wolbers 2003), overeducation (Dolton and Vignoles 2000; Ortiz and Kucel 2008) or temporary employment (Giesecke and Schindler 2008). However, these studies predominantly concentrate their research either on gender differences in returns to education and the mediating role of the field of study or on cross-national variations in the impact of field of study on labour market returns. Very few studies (van de Werfhorst and Kraaykamp 2001; van de Werfhorst 2002) are concerned with the underlying mechanisms for the effect of field of study in general and systematically address the question why fields differ in their value on the labour market. Nevertheless, the existing work clearly shows that graduates in humanities or social sciences earn less than individuals in fields such as engineering or computer science (e.g. Bobbitt-Zeher 2007; Daymont and Andrisani 1984) As to non-pecuniary outcomes the literature more or less indicates the same pattern: graduates from humanities and social sciences have more difficulties at labour market entry than their peers from other fields.

Against this background, the paper wants to shed light on mechanisms that may explain field of study differences in early labour market returns. Why do particularly 'soft fields' come off worse at labour market entry than their peers in other fields? The empirical analyses draw on a German graduate panel (HIS-Absolventenpanel 1997) that contains extensive information 
on the career start of tertiary graduates. ${ }^{1}$ The transition from higher education to work is operationalised with three indicators: duration of job search after graduation, the risk of overeducation and the risk of job mismatch in the first significant job.

Mechanisms for the effect of field of study can be seen from a supply-side or demand-side perspective. Supply-side explanations refer to differences between fields of study in their signalling of potential training costs. The paper argues that employer are able to assess the average expected training costs by means of two criterions, the occupational specificity and selectivity of a study programme. Demand-side explanations are considered as institutionalized relations between fields of study and occupations that possibly mediate field of study differences in early returns (Wolbers 2003; Roksa 2005). This may be particularly true for Germany that is known for strong linkages between educational attainment and occupational destinations.

\section{Theoretical considerations}

Employers hire job candidates on the basis of imperfect information about their true abilities and thus have to rely on individual characteristics that may signal the potential productivity (Spence 1973). In order to keep the training costs as low as possible they predominantly use the educational attainment as an indicator of general abilities, learning aptitude or motivation. Since higher education has become more widespread in the population the educational level may be seen as a less reliable signal of potential productivity. Therefore, employers seem to increasingly take into account the field of study in their hiring decisions (Jackson, Goldthorpe, and Mills 2005). According to which criteria do employers use the fields of study in the selection process?

The job-competition-theory (Thurow 1975) assumes that labour productivity is primarily determined by job characteristics instead of individual traits of a worker. Accordingly, the theory argues that job-specific skills are predominantly acquired on the job. Thus, employers seek to employ those job candidates that indicate the lowest training costs. They rank job applicants into an imaginary labour queue according to their training costs and match it to a second queue of vacant jobs classified on the basis of their requirements. As the field of study indicates different degrees of training costs it determines graduates' relative position in the labour queue.

A deficiency of the job competition theory, however, is the fact that it does not exactly specify the determinants of the training costs. Following Thurow's work the training costs model (Glebbeek, Wim, and Schakelaar 1989) argues that two indicators, occupational specificity and selectivity, signal a field of study's potential training costs. Occupational 
specificity refers to the degree of employability on the labour market. The more specific the preparation or the more narrow the occupational profile of a study programme, the less additional training employers have to invest in graduates' job-specific skills. Thus, a high occupational specificity may improve the match between employer and employee. In contrast, students that graduate in a more general study programme lack occupational skills and require a more cost-intensive on-the-job-training. Thus, they are ranked into lower positions in the labour queue than their peers with specific occupational skills. From a graduate perspective, the ones with a field of study that provides rather general skills can more easily change the job than their peers with a more specific field and therefore have lower costs of accepting a nonmatching job (Robst 2007). From this argumentation follows hypothesis 1: The more specific the field of study, the smoother graduates' transition from higher education to work.

The selectivity of a study programme indicates the average quality of students in terms of motivation, commitment or other cognitive and affective traits (Ishida, Spilerman, and $\mathrm{Su}$ 1997, 868). Selectivity does not only refer to differences between fields but also to ability variation within fields. The more heterogeneous graduates' abilities the higher employers' risk of selecting a graduate that lacks the job requirements. Thus, selective study programmes increase the propensity to choose a job candidate that is able to do the job. Selectivity may be enhanced by closure strategies (Weeden 2002) such as student-in-take restrictions in form of institutionalized selection procedures. In Germany, the Numerus Clausus mostly regulates access to professional studies that are certificated with the degree Staatsexamen. The selection is based on the Abitur grade and waiting terms. Since access to Magister courses predominantly offered in 'soft fields' such as humanities - is less constrained than access to other degrees, the less skilled students may more frequently enrol in these programmes. Due to educational expansion the diversity of skills between different degrees may have even become stronger (Walker and Zhu 2005). Because of a non-selective student population employers may eventually regard 'soft fields' as negative selection criterion. Hypothesis 2 suggests that the more selective the field of study, the smoother graduates' transition from higher education to work.

From a demand-side perspective, the availability of matching jobs and their quantitative importance in the occupational distribution determine a field of study's labour market success. Differences in labour market returns may not only be attributed to characteristics of the field of study itself. Institutionally given pathways into occupational destinations may mediate them as well. The institutional setting in Germany particularly enables employers to use vocational skills for the allocation of individuals into jobs. In such qualificational spaces 
(Maurice, Sellier, and Silvestre 1986) graduates from different fields of study do not compete about the same vacancies and thus cannot be considered on a unidimensional job queue. The framework of dual and segmented labour markets (Doeringer and Piore 1971; Blossfeld and Mayer 1988) assumes that the labour market as a whole is composed of a series of partial labour markets that result from specific institutional regulatory structures and are not open to every market actor to the same degree. In Germany, the institutional framework leads to strong occupational linkages in higher education as well. The link between tertiary education and occupational destinations is particularly close in the case of the professions and the civil service (Müller, Steinmann, and Ell 1998). As a state-controlled training and certifying process restricts the supply of graduates the degree Staatsexamen can be interpreted as one form of licensing that eventually leads to occupational closure (Weeden 2002). Due to these institutionalised pathways students that graduate in professional fields such as medicine, law or teaching should be most advantaged in terms job search and job quality at labour market entry. Overall, the civil service has a bureaucratic structure with hierarchical career possibilities that are linked to specific educational credentials. This circumstance may facilitate tertiary graduates' access to advantageous positions and prevent job competition with graduates from lower educational levels. Hence, in Germany strong institutionalised relations between fields of study and occupational areas - or job characteristics that are more or less prevailing in different segments - are quite plausible and potentially mediate field of study effects at labour market entry (Roksa 2005; Weeden 2002; Wolbers 2003). Consequently, hypothesis 3 suggests that field of study differences in labour market returns are mediated by job characteristics, in particular the employment sector.

Furthermore, occupations differ in their demand for occupational skills that are acquired in specific study programmes (de Wolf and van der Velden 2001). The more task-specific the requirements of a job, the higher the potential training costs for guaranteeing an adequate performance on the job. The higher the extent of training costs, the more important the selection of job candidates that graduated in fields of study which provide occupation-specific expertise. At the same time, strong demand for expertise in a job tend to involve higher labour market returns (Thurow 1975). Thus, hypothesis 4 assumes that field of study differences in non-pecuniary returns are mediated by the task specificity of a job.

\section{Data and measurement}

In order to test the hypotheses I use the 'HIS-Absolventenpanel 1997' which is a representative German panel study of the 1997 graduate cohort (for a more detailed description see Fabian and Minks 2006). The population consists of graduates that acquired 
their first degree at university or second-tier Fachhochschule. The survey was conducted one and five years after graduation and includes extensive information on the course of studies, the transition phase into the labour market and subsequent career development. Moreover, graduates reported their full employment history for the first five years. As to the sample: I exclude graduates that become self-employed or started a second course of studies after graduation. ${ }^{2}$ Graduates who did not finish their second schooling phase (Referendariat, Arzt im Praktikum (AiP)), the $\mathrm{PhD}$ or other postgraduate studies in the first five years are excluded as well.

As dependent variables I use three different non-pecuniary returns: job search duration, risk of overeducation and risk of job mismatch in the first significant job. ${ }^{3}$ Job search duration has to extracted from the employment history and is measured as the period between the month of final degree or the end of a second schooling phase and the beginning month of the first significant employment spell. ${ }^{4}$ While the episodes unemployed, freelance work, to job, internship, advanced training or family work are counted as search time, miscellaneous or parental leave are considered as inactive.

Overeducation represents the vertical dimension of adequacy and is measured with the subjective information whether graduates are adequately employed according to their tertiary degree. Graduates are overeducated in the first significant job if they indicate that tertiary education is either irrelevant or not the standard degree for the current occupational position. In contrast, graduates are adequately employed when answering that a tertiary degree is compulsory or the standard degree.

The risk of job mismatch is also based on a subjective measure and represents the horizontal dimension of adequacy. Graduates were asked in the survey whether they are adequately employed according to their field of study. The pentatonic scale that ranges between yes, definitely (1) and no, definitely not (5) was dichotomised, where categories 3-5 indicate a job mismatch, categories 1-2 a job match.

The single fields of study are condensed into ten broader groups: education, arts, humanities, social and behavioural sciences, business and economics, law, science and mathematics, engineering, agriculture, health and welfare.

Occupational specificity is operationalised by three different indicators. The first objective measure is the Herfindahl index of dispersion (Dekker, de Grip, and Heijke 2002). For each occupation (ISCO-88 3-digit) the index measures whether employees graduated in various fields of study or whether they are recruited from a rather limited spectrum of fields (see 
appendix A2). Thus, it captures an occupation's homogeneity or heterogeneity with regard to employees' fields of study. ${ }^{5}$

The second measure refers to a subjective assessment of the content of study programmes. Graduates were asked whether the practical requirements in curricula are up-to-date (Aktualität bezogen auf Praxisanforderungen) and how they evaluate the practice of jobspecific professional action during their studies (Einübung in beruflich-professionelles Handeln). For both items the answer options range from very good to very bad on a pentatonic scale. Positive answers on these two items may indicate that curricula offer occupation-specific training and prepare students for a narrow job profile. Thus, I built an additive index that is also standardized between 0 and 1, where large values show a high degree occupational specificity and vice versa.

The third measurement refers to the composition of the fields of study. While graduates that study only one subject are considered as most specific, the ones that combine two subjects which do not belong to the same main group represent a high degree of diversity. Joining a major and a minor subject that fall in the same main group is seen as medium category.

A field of study's selectivity is measured with graduates' average Abitur grades as well as the standard deviation of Abitur grades. ${ }^{6}$ The two indicators tend to represent both the level of skills as well as the dispersion of skills around the mean.

With regard to job characteristics I consider temporary vs. permanent and part-time vs. fulltime jobs. Besides, I distinguish between occupations in large firms (more than 1000 employees) and small firms (less than 1000 employees). As to the employment sector I differentiate between private manufacturing, private service and the civil service.

Task specificity is based on subjective information on the importance of professional knowledge in a job. Respondents were able to choose between the categories very important, useful and irrelevant. By use of these answers I calculate for every occupation (ISCO-88 3digit) the average importance of professional knowledge.

Furthermore, I control for various individual characteristics that may be responsible for field of study effects as well (for details see Appendix A1).

\section{Results}

\subsection{The timing of labour market entry}

Table 1 shows the timing of labour market entry by means of Cox regression models (Singer and Willett 2003; Cleves, Gould, and Gutiérrez 2004). The Cox regression requires that the effects of covariates are time-constant and only cause proportional shifts in the hazard rate. A test based on Schoenfeld residuals (Cleves, Gould, and Gutiérrez 2004, 200), however, 
indicates that in case of the field of study the assumption of proportional hazards does not hold. Therefore, I specify nonproportional hazard models that permit the field of study effects to vary linearly over time (Singer and Willett 2003, 562). Specifically, the models include interaction parameters between the fields of study and the logarithm of time. To facilitate interpretation I use $\operatorname{logs}$ to the base of 2 meaning that the interaction terms represent the change in log hazard differences as the length of job search doubles.

Table 1 indicates three nested models: the first one only controls for the individual characteristics, the second model takes the specificity indicators into account and the third one holds selectivity constant. At the beginning of the job search (main effects) every field of study has a significantly lower rate of job entry in reference to health and welfare holding individual characteristics contstant. ${ }^{7}$ Difficulties in finding a job directly after graduation are most pronounced for graduates from arts, social sciences and somewhat less for humanities. The significantly positive interaction parameters for most fields of study proof again that the assumption of proportional hazards is not given. The longer the search time the lower the differences in the job finding rate between the other fields of study and health/welfare. Beside education and science particularly graduates from 'soft fields' seem to remain disadvantaged in finding a job when search time proceeds.

Model 2 shows that the objective measure of the Herfindahl-index leads to a significant reduction in the rate of job entry. The more selective employers hire job applicants from a limited set of fields of study the higher the job finding rates for these jobs. ${ }^{8}$ In contrast, the content specificity has no significant impact on the hazard rate. As to the third indicator: graduates who study different fields in the same main group have a significantly lower job finding rate than their peers that graduate from one subject only. A high diversity in the combination of fields of study also has a negative impact on the hazard rate but is not significant at conventional criteria. By introducing the specificity measures particularly the main effects for the 'soft fields' (e.g. for humanities from -0.65 to -0.46 ) are reduced, though are still highly significant.

\section{(Table 1)}

According to model 3 better average Abitur grades are associated with a significantly faster job finding. Thus, graduates from highly selective fields have advantages in the job search process. Controlling for the mean the dispersion of skills has no significant impact on the hazard rate. The main effects of the 'soft fields' become slightly smaller. Due to a less selective student population in comparison to health/welfare the effects of education and agriculture are particularly reduced. However, as the parameters are less reduced between 
model 2 and 3 than between model 1 and 2 field of study differences may be more attributed to specificity than selectivity.

Across the three models the interaction parameters keep quite stable. Hence, the supply-side explanations are only effective for the beginning of the search time, where differences between fields of study are most pronounced. Overall, large differences in job findings rates persist even though controlling for supply-side explanations.

\subsection{The risk of overeducation}

Concerning the risk of overeducation or job mismatch table 2 and table 3 present $\mathrm{y}^{*}$ standardized coefficients which allow the comparison of estimates across nested logistic models (Winship and Mare 1984; Mood 2010). ${ }^{9}$ The first three models are identical to the ones on job search duration. The fourth model additionally controls for job characteristics that may mediate field of study differences in the risk of overeducation or job mismatch.

Apart from law all graduates have a significantly higher risk of being overeducated than their peers from health and welfare. Holding the individual variables constant graduates from humanities, arts and agriculture have the highest risk of underutilizing their skills in the first significant job.

The second model shows a significant impact of the Herfindahl-index: The more homogenous the composition of employees according to their field of study, the lower the individual risk of being overeducated. Job applicants are also less likely affected by overeducation when they graduated from a field that provides occupation-specific skills in curricula. The effect is significant at the 5\%-level. Thus, specificity has a positive impact on labour market rewards according to one rather objective and one subjective indicator. In contrast, the diversity of fields of study has no significant impact on overeducation. Holding the three different forms of specificity constant, the standardized parameters for the 'soft fields' and science are slightly reduced. As to the other fields of study the effects remain rather constant. These fields of study do not differ much from the reference health and welfare in terms of occupational specificity. Only in the case of 'soft fields', such as humanities or social sciences, and science occupational specificity tends to partially explain differences in the risk of overeducation.

As to the selectivity measures in the third model: the better the average Abitur grades in a field of study the lower the risk of overeducation for individuals that graduated in this field. However, the dispersion of skills has no impact on the risk of overeducation. By controlling average Abitur grades in particular the standardized parameters for education, engineering and agriculture are reduced. This is due to the fact that fields of study in these main groups on average have worse Abitur grades than fields in the group health and welfare. The reverse 
pattern can be seen for law and particularly science which have on average better Abitur grades than health/welfare. Thus, selectivity seems to account for part of the differences between fields of study as well.

\section{(Table 2)}

According to the fourth model, graduates who work part-time have a higher risk of underutilizing their skills in the first significant job. Temporary employment and firm size, however, do not significantly affect the risk of overeducation. When employed in the public sector instead of any private sector graduates have a substantially higher propensity to work in an adequate job that matches their educational degree. Holding all other variables constant the effect indicates that selection procedures in the civil service are much more based on formal education than in the private sector. Although occupational task specificity tends to prevent overeducation, due to a large standard error the impact is not significant at conventional criteria. According to a likelihood-ratio test the single variable significantly improves the model fit at least at the 5\%-level. By holding job characteristics constant the standardized parameters for all fields of study except education and law substantially decrease from model 3 to model 4. For the relevant studies the share of graduates that finds employment in the civil service is considerably lower than in health and welfare. Taking all mechanisms into account there are no significant differences between the fields of study and the reference health and welfare. However, changing the reference to engineering, humanities, education and business are still significantly disadvantaged in terms of overeducation. Nevertheless, in comparison to model 1 particularly the standardized parameters for the 'soft fields' are largely reduced. Even though taking demand-side characteristics into account two indicators of specificity, the Herfindahl-index and content specificity, as well as the average Abitur grades remain significant.

\subsection{The risk of job mismatch}

With regard to job mismatch table 3 involves the same model comparisons as in the case overeducation. The first model indicates that graduates from all fields of study except law and arts have a significantly higher risk of horizontal job mismatch than their peers from health and welfare. Again, graduates from humanities and social sciences are least successful in finding jobs that match their field of study.

According to the second model both the Herfindahl-index and the measure of content specificity significantly reduce the risk of job mismatch. Moreover, a medium level of diversity in the composition of fields of study significantly increases the risk of being mismatched in the first significant job. In contrast to expectations, a high level of diversity 
does not have an impact on the propensity of having a job mismatch. Controlling for specificity the standardized parameters of fields of study towards health and welfare are reduced, in particular for humanities and social sciences.

The third model shows that both selectivity measures have no significant impact on the risk of job mismatch. A likelihood-ratio test also illustrates that the two indicators do not contribute to a significant improvement of the model fit. Accordingly the standardized parameters for the fields of study only change marginally. Thus, differences between fields of study in job matching procedures cannot be attributed to the selectivity of study programmes.

\section{(Table 3)}

Model 4 additionally controls for job characteristics. While a part-time job, fixed-term contract and the firm size seem to have no impact on the risk of job mismatch, employment in the civil service significantly prevents a horizontal mismatch between employer and employee. Thus, graduates that find a job in the civil service have advantages both in vertical and horizontal terms of educational adequacy. The task specificity of a job also has a significant impact on the risk of job mismatch. The more professional knowledge a job demands the lower the risk of employees to be mismatched according to their field of study. In other words, employers that require very specific skills for the vacant jobs at hand also put more emphasis on job applicants' horizontal qualification in the selection process than the ones where occupation-specific skills are of less importance. By controlling for job characteristics the standardized coefficients for the field of study effects are largely reduced. Again, this is due to substantial differences in the share of civil service positions and taskspecific jobs between health and welfare and the other fields of study. Even though holding all potential mechanisms constant differences between some fields of study still remain. For instance, the high risk of job mismatch for graduates from education persists even though the transition into teaching jobs is highly institutionalized and the course of studies should be much more occupation-specific than in other fields.

\section{Conclusion}

The paper focuses on underlying mechanisms that may explain differences between fields of study in early labour market returns. More specifically, I ask why in particular 'soft fields' such as humanities or social sciences are disadvantaged at labour market entry. From a supply-side perspective, the fields of study may signal different amounts of trainings costs to employers. Based on an extension of the labour queue model the training costs are determined by two components: occupational specificity and selectivity. According to the model 
employers prefer those job candidates that graduate in fields of study which involve a high degree of occupational specificity and selectivity.

From a demand-side perspective, it is argued that graduates from different fields of study do not compete about the same vacancies and have different access chances to partial labour markets that are more or less beneficial in terms of labour market rewards. This may be particularly relevant for Germany where strong institutional linkages between education and the occupational system are prevailing. As to higher education more or less prescribed occupational pathways exist for the professions and the civil service. Therefore, I assume that the strong relationship between fields of study and specific occupational areas may mediate the impact of field of study on the risk of overeducation and job mismatch.

While the transition from school to work is the smoothest for graduates from health and welfare according to all indicators, graduates from 'soft fields' are considerably disadvantaged at labour market entry.

As to the first mechanism of occupational specificity: at least the objective measure of the Herfindahl-index has a significant impact on all labour market returns. A low dispersion significantly reduces job search duration, the risk of overeducation and job mismatch. In particular in the case of overeducation it has a strong impact. In contrast, the subjective measure of content specificity has its most influential effect on job mismatch. While it also decreases the risk of overeducation, the content specificity has no impact on the speed of labour market entry. The third indicator produces rather mixed results: Only medium diversity - the combination of fields of study that belong to the same main group - prolongs job search duration and increases the risk of job mismatch. High diversity does not differ from low diversity. Apparently, the combination of very different studies increases the range of possibilities to find a (matching) job.

The selectivity of a study programme - operationalised with the average Abitur grades - has a positive impact on the speed of labour market entry and reduces the risk overeducation. In contrast, the dispersion of skills around the mean does not contribute to the explanation of differences in labour market rewards, in particular job mismatch. Hence, the between-field variation in graduates' skill composition seems to be more important than within-field variation.

From a demand-side perspective the results show that the employment sector strongly affects non-pecuniary labour market returns. Graduates that work in the civil service have a significantly lower risk of overeducation and job mismatch. In the private industry, employment in service or manufacturing does not make a difference in terms of non- 
pecuniary outcomes. As to overeducation the effect of the civil service illustrates that it enables very strict hierarchical career possibilities that are linked to specific educational credentials. Thus, in the civil service graduates from higher education are protected against increasing job competition that is due to educational expansion. As to job mismatch, the effect indicates that the link between fields of study and occupational destinations is particularly high in the civil service. In particular, graduates from the professions pass through institutionalized pathways into occupational positions in the civil service.

The analyses also reveal that the task specificity of a job significantly decreases the risk of having a job mismatch. The more a job requires specific expertise, the more probable the job tasks assort well with the acquired skills in the study programme. Thus, both on the side of education and occupation specific requirements increase the chances of an immediate match between employer and employee in the labour market.

Controlling for both supply- and demand-side characteristics, the field of study differences are substantially reduced, in particular for the most disadvantaged 'soft fields'. Therefore, all hypotheses can be more or less confirmed. However, in particular in the case of job search duration considerable differences in job finding rates remain. This is possibly due to the fact that I am not able to control for demand-side characteristics. Looking at the reduction of field of study parameters, it seems that demand-side considerations are by far more important in explaining different labour market returns. The mediating effects of the civil service and task specificity stress the necessity of considering the occupational and organisational context in the study of labour market outcomes. In this paper, measures of demand are, however, only approximated. It would be helpful to incorporate measures of demand or demand-supplyratios that are rather independent of the current occupational distribution.

Nevertheless, holding demand-side characteristics constant the remaining supply-side effects are quite remarkable. Above all, occupational specificity tends to enable a faster and more adequate match between employer and employee in the labour market. The Bologna-process and its adjustments towards the Bachelor's-Master's structure precisely intend to provide graduates - in particular in the 'soft fields' - with stronger occupation-specific skills. Thus, further research should also have a look on the temporal development of field of study differences in labour market returns and possibly changing mechanisms after the process. 


\section{References}

Biglan, A. 1973. Characteristics of Subject Matter in Different Academic Areas. Journal of Applied Psychology 57: 195-203.

Blossfeld, H.-P., and K.U. Mayer. 1988. Arbeitssegmentation in der Bundesrepublik Deutschland. Kölner Zeitschrift für Soziologie und Sozialpsychologie 40: 282-283.

Bobbitt-Zeher, D. 2007. The Gender Income Gap and the Role of Education. Sociology of Education 80: 1-22.

Cleves, M., W. Gould, and R. Gutiérrez. 2004. An Introduction to Survival Analysis Using Stata. College Station, Texas: Stata Press.

Daymont, T.N., and P.J. Andrisani. 1984. Job Preferences, College Major, and the Gender Gap in Earnings. Journal of Human Resources 19: 408-428.

de Wolf, I., and R.K.W. van der Velden. 2001. Selection Processes for Three Types of Academic Jobs. An Experiment among Dutch Employers of Social Science Graduates. European Sociological Review 17: 317-330.

Dekker, R., A. de Grip, and H. Heijke. 2002. The Effects of Training and Overeducation on Career Mobility in a Segmented Labour Market. International Journal of Manpower 23: 106-125.

Doeringer, P.B., and M.J. Piore. 1971. Internal Labour Markets and Manpower Analysis. Lexington (Mass.): Heath.

Dolton, P., and A. Vignoles. 2000. The Incidence and Effects of Overeducation in the U.K. Graduate Labour Market. Economics of Education Review 19: 179-198.

Fabian, G., and K.-H. Minks. 2006. Dokumentation des Scientific Use Files "HISAbsolventenpanel 1997" Hannover: Hochschul-Informations-System.

Fox, J. 1997. Applied Regression Analysis, Linear Models, And Related Methods. Thousand Oaks: Sage Publications.

Gerhart, B. 1990. Gender Differences in Current and Starting Salaries - the Role of Performance, College Major and Job Title. Industrial \& Labor Relations Review 43: 418-433.

Giesecke, J., and S. Schindler. 2008. Field of Study and Flexible Work. A Comparison between Germany and the UK. International Journal of Comparative Sociology 49: 283-304.

Glebbeek, A., N. Wim, and R. Schakelaar. 1989. The Labor-Market Position of Dutch Sociologists - An Investigation Guided by a Theoretical Model. Netherlands Journal of Social Sciences 25: 57-74.

Hansen, M.N. 2001. Education and Economic Rewards: Variations by Social-Class Origin and Income Measures. European Sociological Review 17: 209-231.

Ishida, H., S. Spilerman, and K.-H. Su. 1997. Educational Credentials and Promotion Chances in Japanese and American Organizations. American Sociological Review 62: 866-882.

Jackson, M., J.H. Goldthorpe, and C. Mills. 2005. Education, Employers and Class Mobility. Research in Social Stratification and Mobility 23: 3-33.

Kalmijn, M., and T. Van der Lippe. 1997. Type of Schooling and Sex Differences in Earnings in the Netherlands. European Sociological Review 13: 1-15.

Katz-Gerro, T., and M. Yaish. 2003. Higher Education: Is More Better? Gender Differences in Labour Market Returns to Tertiary Education in Israel. Oxford Review of Education 29: 571-592.

Kim, A., and K. Kim. 2003. Returns to Tertiary Education in Germany and the UK: Effects of Field of Study and Gender. MZES Working Paper 62: 1-35.

Long, J.S., and J. Freese. 2006. Regression models for Categorical Dependent Variables using Stata (2. ed.). College Station, Tex.: Stata Pr. 
Loury, L.D. 1997. The Gender Earnings Gap among College Educated Workers. Industrial \& Labor Relations Review 50: 580-593.

Marini, M.M., and P.L. Fan. 1997. The Gender Gap in Earnings at Career Entry. American Sociological Review 62: 588-604.

Maurice, M., F. Sellier, and J. Silvestre. 1986. The Social Foundations of Industrial Power: A Comparison of France and Germany. Cambridge, MA: MIT Press.

Mood, C. 2010. Logistic Regression: Why We Cannot Do What We Think We Can Do, and What We Can Do About It. European Sociological Review 26: 67-82.

Müller, W., S. Steinmann, and R. Ell. 1998. Education and Labour-Market Entry in Germany. In Y. Shavit \& W. Müller (Eds.), From School to Work. A Comparative Study of Educational Qualifications and Occupational Destinations. (pp. 143-188). Oxford: Clarendon Press.

Ortiz, L., and A. Kucel. 2008. Do Fields of Study Matter for Over-education?: The Cases of Spain and Germany. International Journal of Comparative Sociology 49: 305-327.

Reimer, D., C. Noelke, and A. Kucel. 2008. Labor Market Effects of Field of Study in Comparative Perspective: An Analysis of 22 European Countries. International Journal of Comparative Sociology 49: 233-256.

Reimer, D., and S. Steinmetz. 2009. Highly Educated but in the Wrong Field? Educational Specialisation and Labour Market Risks of Men and Women in Spain and Germany in Higher Education. European Societies 11: 723-746.

Robst, J. 2007. Education and Job Match: The Relatedness of College Major and Work. Economics of Education Review 26: 397-407.

Roksa, J. 2005. Double Disadvantage or Blessing in Disguise? Understanding the Relationship Between College Major and Employment Sector. Sociology of Education 78: 207-232.

Shwed, U., and Y. Shavit. 2006. Occupational and Economic Attainment of College and University Graduates in Israel. European Sociological Review 22: 431-442.

Singer, J.D., and J.B. Willett. 2003. Applied Longitudinal Analysis: Modelling Change and Event Occurrence. New York: Oxford University Press.

Smyth, E. 2005. Gender Differentiation and Early Labour Market Integration Across Europe. European Societies 7: 451-479.

Spence, M. 1973. Job Market Signalling. Quarterly Journal of Economics 87: 355-374.

Thurow, L.C. 1975. Generating Inequality. New York: Basic Books.

van de Werfhorst, H.G. 2002. Fields of study, Acquired Skills and the Wage Benefit from a Matching Job. Acta Sociologica 45: 287-303.

van de Werfhorst, H.G., and G. Kraaykamp. 2001. Four Field-related Educational Resources and Their Impact on Labor, Consumption, and Sociopolitical Orientation. Sociology of Education 74: 296-317.

Walker, I., and Y. Zhu. 2005. The College Wage Premium, Overeducation and the Expansion of Higher Education in the UK. IZA Discussion Paper No. 1627.

Weeden, K.A. 2002. Why Do Some Occupations Pay More Than Others? Social Closure and Earnings Inequality in the United States. American Journal of Sociology 108: 55-101.

Winship, C., and R.D. Mare. 1984. Regression Models with Ordinal Variables. American Sociological Review 49: 512-525.

Wolbers, M.H.J. 2003. Job Mismatches and their Labour-Market Effects among SchoolLeavers in Europe. European Sociological Review 19: 249-266. 


\section{Notes}

1 The data from 1997 characterise the German higher education system in the pre-Bologna-Process. At the present higher education is differentiated in a bachelor's and master's degree. Moreover, the so-called Exzellenzinitiative tends to establish stronger hierarchical levels between universities in terms of prestige. As the internal differentiation and the accentuation of single universities may complicate the analysis of field of study mechanisms, the 'old' data seem to be advantageous.

${ }^{2}$ The sample is restricted because the hypotheses do not refer to self-employed. As to graduates with a further field of study the dataset lacks additional information.

${ }^{3}$ I only have information on job characteristics for the first (not implicitly the first significant one according to the relevant question) and current job in the first and second wave. If the first significant job that is extracted from the employment history is not equivalent with the first job in the dataset and does not fall in the period of the first or second wave, I do not have further information on this job. Therefore, the sample size is smaller for the analyses on overeducation and job mismatch than for the job search.

${ }^{4}$ The first significant employment does not include stop-gap jobs or marginal employments (all kinds of minor work such as internships, summer jobs or other casual employment). The variable search time contains 103 (1.78 \%) right-censored cases.

${ }^{5}$ For those graduates who did not find a job I assign the mean value of occupation-based dispersion from their field of study. Due to perfect collinearity I cannot estimate the effects of the fields of study and a measure of the dispersion of occupations in fields in the same model. Thus, I consider the occupation-based dispersion index as a proxy of a field's occupational specificity. In the original formula the range is between zero and one, where higher values indicate a more heterogeneous distribution. In order to ease interpretation the pattern is reversed.

${ }^{6}$ The Abitur is the necessary requirement for the entitlement to higher education in Germany. For some fields of study requiring Numerus Clausus the average Abitur grades are important prerequisites for admission. In Germany grades range between 1 and 6 where 1 represents the best grade and 6 the worst. In order to ease interpretation the average Abitur grades and the standard deviation are reversed.

${ }^{7}$ In every analysis health and welfare is the reference category because its graduates have the smoothest transition according to all indicators.

${ }^{8}$ However, the effect has to be seen with caution as there might be endogeneity problems. 
${ }^{9}$ The standardization was calculated with the STATA-ado listcoeff (Long \& Freese, 2006). The $\mathrm{y}^{*}$-standardized coefficients can be interpreted as follows: for a unit increase in $\mathrm{x}_{\mathrm{k}}$, $\mathrm{y}^{*}$ increases or decreases by $\beta_{\mathrm{k}}$ standard deviations, holding all other variables constant. 
Table 1 The transition into the first significant job: log hazard rate effects.

\begin{tabular}{|c|c|c|c|}
\hline & $\mathbf{M 1}^{\mathbf{a}}$ & $\mathbf{M 2}^{\mathbf{a}}$ & $\mathbf{M 3}^{\mathbf{a}}$ \\
\hline \multicolumn{4}{|l|}{ Field of study (ref. Health/Welfare) } \\
\hline Education & $-0.22^{* * *}(0.05)$ & $-0.24^{* * *}(0.05)$ & $-0.16^{* *}(0.05)$ \\
\hline Arts & $-1.03^{* * *}(0.18)$ & $-0.95^{* * *}(0.18)$ & $-0.89^{* * *}(0.18)$ \\
\hline Humanities & $-0.65^{* * *}(0.10)$ & $-0.46^{* * *}(0.10)$ & $-0.44^{* * *}(0.10)$ \\
\hline Social sciences & $-0.83^{* * *}(0.10)$ & $-0.71^{* * *}(0.11)$ & $-0.66^{* * *}(0.11)$ \\
\hline Business/Economics & $-0.54^{* * *}(0.06)$ & $-0.48^{* * *}(0.06)$ & $-0.47^{* * *}(0.06)$ \\
\hline Law & $-0.45^{* * *}(0.09)$ & $-0.40^{* * *}(0.09)$ & $-0.48^{* * *}(0.09)$ \\
\hline Science & $-0.29^{* * *}(0.06)$ & $-0.20^{* * *}(0.06)$ & $-0.27^{* * *}(0.06)$ \\
\hline Engineering & $-0.56^{* * *}(0.05)$ & $-0.57^{* * *}(0.05)$ & $-0.48^{* * *}(0.05)$ \\
\hline Agriculture & $-0.61^{* * *}(0.14)$ & $-0.61^{* * *}(0.14)$ & $-0.49^{* * *}(0.14)$ \\
\hline \multicolumn{4}{|l|}{ Interactions with time } \\
\hline Education $\times \log _{2}($ time $)$ & $0.08(0.04)$ & $0.09^{*}(0.04)$ & $0.09^{*}(0.04)$ \\
\hline Arts $\times \log _{2}($ time $)$ & $0.20^{*}(0.09)$ & $0.20^{*}(0.09)$ & $0.18^{*}(0.09)$ \\
\hline Humanities $\times \log _{2}($ time $)$ & $0.10^{*}(0.05)$ & $0.10^{*}(0.05)$ & $0.10^{*}(0.05)$ \\
\hline Social sciences $\times \log _{2}$ (time) & $0.17^{* * *}(0.05)$ & $0.17^{* * *}(0.05)$ & $0.17^{* * *}(0.05)$ \\
\hline Business/Economics $\times \log _{2}$ (time) & $0.27^{* * *}(0.04)$ & $0.27^{* * *}(0.04)$ & $0.26^{* * * *}(0.04)$ \\
\hline Law $\times \log _{2}($ time $)$ & $0.33^{* * * *}(0.06)$ & $0.33^{* * *}(0.06)$ & $0.32^{* * *}(0.06)$ \\
\hline Science $\times \log _{2}($ time $)$ & $0.09^{*}(0.04)$ & $0.08(0.04)$ & $0.07(0.05)$ \\
\hline Engineering $\times \log _{2}($ time $)$ & $0.20^{* * *}(0.04)$ & $0.20^{* * *}(0.04)$ & $0.19^{* * *}(0.04)$ \\
\hline Agriculture $\times \log _{2}($ time $)$ & $0.24^{* *}(0.07)$ & $0.22^{* *}(0.07)$ & $0.22^{* *}(0.08)$ \\
\hline \multicolumn{4}{|l|}{ Specificity } \\
\hline Herfindahl-index & & $0.36^{* * *}(0.06)$ & $0.31^{* * *}(0.06)$ \\
\hline Content specificity & & $0.11(0.08)$ & $0.14(0.08)$ \\
\hline \multicolumn{4}{|l|}{ Diversity (ref. Low) } \\
\hline Medium & & $-0.30^{* * *}(0.09)$ & $-0.30^{* * *}(0.09)$ \\
\hline High & & $-0.17(0.11)$ & $-0.13(0.11)$ \\
\hline \multicolumn{4}{|l|}{ Selectivity } \\
\hline Average Abitur grade & & & $0.05^{* * *}(0.01)$ \\
\hline SD Abitur grade & & & $0.01(0.04)$ \\
\hline $\mathrm{N}$ & 4951 & 4951 & 4951 \\
\hline Wald $\mathrm{Chi}^{2}$ & $411.48^{* * *}$ & $470.87^{* * *}$ & $509.03^{* * *}$ \\
\hline
\end{tabular}

Note: Robust standard errors in parentheses; ${ }^{\mathrm{a}}=$ controlling for individual characteristics (see Appendix A2). Source: HIS Graduate Panel 1997, own calculations; ${ }^{*} p<0.05 ;{ }^{* *} p<0.01 ;{ }^{* * *} p<0.001$ 
Table 2 The risk of overeducation in the first significant job.

\begin{tabular}{|c|c|c|c|c|}
\hline & $\mathbf{M 1}^{\mathrm{a}}$ & $\mathbf{M 2}^{\mathbf{a}}$ & $\mathbf{M 3}^{\mathbf{a}}$ & $\mathbf{M} 4^{\mathrm{a}}$ \\
\hline \multicolumn{5}{|c|}{ Field of study (ref. Health/Welfare) } \\
\hline Education & $0.38^{* *}(0.26)$ & $0.40^{* * *}(0.26)$ & $0.26(0.28)$ & $0.26(0.31)$ \\
\hline Arts & $0.80^{* *}(0.61)$ & $0.71^{*}(0.61)$ & $0.66^{*}(0.60)$ & $0.36(0.63)$ \\
\hline Humanities & $0.93^{* * *}(0.30)$ & $0.71^{* * *}(0.34)$ & $0.66^{* * *}(0.33)$ & $0.35(0.38)$ \\
\hline Social sciences & $0.58^{* * *}(0.31)$ & $0.37^{*}(0.33)$ & $0.32^{*}(0.35)$ & $0.09(0.36)$ \\
\hline Business/Economics & $0.56^{* * *}(0.25)$ & $0.59^{* * *}(0.26)$ & $0.59^{* * *}(0.25)$ & $0.25(0.30)$ \\
\hline Law & $0.05(0.34)$ & $-0.11(0.35)$ & $0.06(0.35)$ & $-0.08(0.38)$ \\
\hline Science & $0.36^{*}(0.28)$ & $0.19(0.29)$ & $0.33^{*}(0.29)$ & $0.02(0.34)$ \\
\hline Engineering & $0.36^{* *}(0.24)$ & $0.36^{* *}(0.24)$ & $0.23(0.25)$ & $-0.09(0.28)$ \\
\hline Agriculture & $0.79^{* * *}(0.39)$ & $0.78^{* * *}(0.39)$ & $0.56^{* *}(0.40)$ & $0.24(0.42)$ \\
\hline \multicolumn{5}{|l|}{ Specificity } \\
\hline Herfindahl-index & & $-0.73^{* * *}(0.24)$ & $-0.68^{* * *}(0.24)$ & $-0.64^{* * *}(0.26)$ \\
\hline Content specificity & & $-0.34^{*}(0.33)$ & $-0.39^{*}(0.34)$ & $-0.38^{*}(0.34)$ \\
\hline \multicolumn{5}{|l|}{ Diversity (Ref. low) } \\
\hline Medium & & $0.09(0.30)$ & $0.07(0.30)$ & $0.04(0.30)$ \\
\hline High & & $-0.13(0.37)$ & $-0.20(0.38)$ & $-0.15(0.38)$ \\
\hline \multicolumn{5}{|l|}{ Selectivity } \\
\hline Average Abitur grade & & & $-0.09^{* * *}(0.04)$ & $-0.08^{* * *}(0.04)$ \\
\hline SD Abitur grade & & & $-0.12(0.19)$ & $-0.16(0.19)$ \\
\hline \multicolumn{5}{|l|}{ Job characteristics } \\
\hline Part-time job & & & & $0.19^{*}(0.17)$ \\
\hline Fixed-term contract & & & & $0.01(0.13)$ \\
\hline Large firm & & & & $-0.09(0.13)$ \\
\hline \multicolumn{5}{|c|}{ Employment sector (Ref. Private manufacturing) } \\
\hline Civil service & & & & $-0.58^{* * *}(0.19)$ \\
\hline Private service & & & & $-0.08(0.14)$ \\
\hline Task specificity & & & & $-1.09(1.60)$ \\
\hline $\mathrm{N}$ & 3556 & 3556 & 3556 & 3556 \\
\hline Wald $\mathrm{Chi}^{2}$ & $269.2^{* * *}$ & $312.6^{* * *}$ & $343.4^{* * *}$ & $416.5^{* * *}$ \\
\hline LR Test & & $50.59_{(4)}^{* * *}$ & $25.31_{(2)}{ }^{* * *}$ & $93.16_{(6)}{ }^{* * *}$ \\
\hline Pseudo $\mathrm{R}^{2}$ & 0.095 & 0.110 & 0.117 & 0.145 \\
\hline
\end{tabular}

Note: $\mathrm{y}^{*}$-standardized coefficients; robust standard errors in parentheses; ${ }^{\mathrm{a}}=$ controlling for individual characteristics (see Appendix A2).

Source: HIS Graduate Panel 1997, own calculations; ${ }^{*} p<0.05 ;{ }^{* *} p<0.01 ;{ }^{* * *} p<0.001$ 
Table 3 The risk of job mismatch in the first significant job.

\begin{tabular}{|c|c|c|c|c|}
\hline & M1 $1^{\mathrm{a}}$ & $\mathbf{M} 2^{\mathrm{a}}$ & $\mathbf{M 3}^{\mathbf{a}}$ & M4 ${ }^{\mathrm{a}}$ \\
\hline \multicolumn{5}{|c|}{ Field of study (ref. Health/Welfare) } \\
\hline Education & $0.60^{* * *}(0.19)$ & $0.58^{* * *}(0.19)$ & $0.60^{* * *}(0.20)$ & $0.45^{* * *}(0.22)$ \\
\hline Arts & $0.44(0.52)$ & $0.38(0.51)$ & $0.40(0.51)$ & $0.06(0.51)$ \\
\hline Humanities & $0.89^{* * *}(0.24)$ & $0.63^{* * *}(0.26)$ & $0.62^{* * *}(0.26)$ & $0.20(0.29)$ \\
\hline Social sciences & $0.76^{* * *}(0.24)$ & $0.58^{* * *}(0.25)$ & $0.61^{* * *}(0.26)$ & $0.33^{*}(0.27)$ \\
\hline Business/Economics & $0.46^{* * *}(0.19)$ & $0.39^{* * *}(0.19)$ & $0.40^{* * *}(0.19)$ & $-0.08(0.23)$ \\
\hline Law & $0.15(0.26)$ & $0.00(0.26)$ & $-0.02(0.26)$ & $-0.21(0.28)$ \\
\hline Science & $0.48^{* * *}(0.20)$ & $0.38^{* * *}(0.21)$ & $0.36^{* * *}(0.21)$ & $-0.03(0.24)$ \\
\hline Engineering & $0.63^{* * *}(0.18)$ & $0.61^{* * *}(0.18)$ & $0.61^{* * *}(0.19)$ & $0.24^{*}(0.21)$ \\
\hline Agriculture & $0.46^{* *}(0.33)$ & $0.44^{*}(0.34)$ & $0.44^{*}(0.34)$ & $0.15(0.36)$ \\
\hline \multicolumn{5}{|l|}{ Specificity } \\
\hline Herfindahl-index & & $-0.41^{* * *}(0.18)$ & $-0.42^{* * *}(0.18)$ & $-0.42^{* *}(0.20)$ \\
\hline Content specificity & & $-0.78^{* * *}(0.25)$ & $-0.78^{* * *}(0.25)$ & $-0.79^{* * *}(0.25)$ \\
\hline \multicolumn{5}{|l|}{ Diversity (Ref. Low) } \\
\hline Medium & & $0.40^{* *}(0.24)$ & $0.41^{* *}(0.24)$ & $0.38^{* *}(0.25)$ \\
\hline High & & $-0.03(0.30)$ & $-0.03(0.31)$ & $-0.02(0.31)$ \\
\hline \multicolumn{5}{|l|}{ Selectivity } \\
\hline Average Abitur grade & & & $0.00(0.03)$ & $0.01(0.03)$ \\
\hline SD Abitur grade & & & $-0.06(0.16)$ & $-0.10(0.15)$ \\
\hline \multicolumn{5}{|l|}{ Job characteristics } \\
\hline Part-time job & & & & $-0.05(0.13)$ \\
\hline Fixed-term contract & & & & $-0.09(0.10)$ \\
\hline Large firm & & & & $-0.03(0.10)$ \\
\hline \multicolumn{5}{|c|}{ Employment sector (Ref. Private manufacturing) } \\
\hline Civil service & & & & $-0.35^{* * *}(0.14)$ \\
\hline Private service & & & & $-0.02(0.11)$ \\
\hline Task specificity & & & & $-2.38^{* * *}(1.17)$ \\
\hline $\mathrm{N}$ & 3556 & 3556 & 3556 & 3556 \\
\hline Wald $\mathrm{Chi}^{2}$ & $189.8^{* * *}$ & $248.7^{* * *}$ & $250.6^{* * *}$ & $340.0^{* * *}$ \\
\hline LR Test & & $73.58_{(4)}{ }^{* * *}$ & $1.04_{(2)}$ & $125.78_{(6)}{ }^{* * *}$ \\
\hline Pseudo $\mathrm{R}^{2}$ & 0.052 & 0.068 & 0.068 & 0.096 \\
\hline
\end{tabular}

Note: $\mathrm{y}^{*}$-standardized coefficients; robust standard errors in parentheses; ${ }^{\mathrm{a}}=$ controlling for individual characteristics (see Appendix A2).

Source: HIS Graduate Panel 1997, own calculations; ${ }^{*} p<0.05 ;{ }^{* *} p<0.01 ;{ }^{* * *} p<0.001$ 


\section{Figure A1: The Herfindahl-Index}

$$
D o=\left(1-\sum_{O=1}^{O}\left(\frac{G_{o f}}{G o}\right)^{2}\right) \frac{F}{F-1}
$$

$\mathrm{D}_{\mathrm{o}}=$ dispersion of fields of study for occupations (ISCO-88 3-digits) o

$\mathrm{G}_{\mathrm{of}}=$ number of graduates in occupation o with field of study $\mathrm{f}$

$\mathrm{G}_{\mathrm{o}}=$ number of graduates in occupation $\mathrm{o}$

$\mathrm{O}=$ total number of ISCO-88 3-digits 
Appendix A2 Descriptive Statistics

\begin{tabular}{|c|c|c|c|}
\hline Variables & Min/Max & Mean & SD \\
\hline \multicolumn{4}{|l|}{ Dependent variables } \\
\hline Job Search Duration (in months) & $1 / 77$ & 4.70 & 8.13 \\
\hline \multicolumn{4}{|l|}{ Overeducation in first significant job } \\
\hline Yes & $0 / 1$ & 17.44 & - \\
\hline No & $0 / 1$ & 82.56 & - \\
\hline \multicolumn{4}{|l|}{ Job Mismatch in first significant job } \\
\hline Yes & $0 / 1$ & 35.15 & - \\
\hline No & $0 / 1$ & 64.85 & - \\
\hline \multicolumn{4}{|l|}{ Field of study (main groups) } \\
\hline Health and Welfare & $0 / 1$ & 10.12 & - \\
\hline Education & $0 / 1$ & 14.64 & - \\
\hline Arts & $0 / 1$ & 1.35 & - \\
\hline Humanities & $0 / 1$ & 5.53 & - \\
\hline Social Sciences & $0 / 1$ & 4.93 & - \\
\hline Business/Economics & $0 / 1$ & 17.19 & - \\
\hline Law & $0 / 1$ & 4.75 & - \\
\hline Science & $0 / 1$ & 12.79 & - \\
\hline Engineering & $0 / 1$ & 25.15 & - \\
\hline Agriculture & $0 / 1$ & 3.55 & - \\
\hline \multicolumn{4}{|l|}{ Specificity $^{l}$} \\
\hline Herfindahl-index (occupational level) & $0 / 1$ & 0.52 & 0.24 \\
\hline Content Specificity (individual level) & $0 / 1$ & 0.30 & 0.17 \\
\hline \multicolumn{4}{|l|}{ Diversity } \\
\hline Low & $0 / 1$ & 95.15 & - \\
\hline Medium & $0 / 1$ & 2.99 & - \\
\hline High & $0 / 1$ & 1.86 & - \\
\hline \multicolumn{4}{|l|}{ Selectivity (by single field of study) } \\
\hline Average Abitur grades & $1.77 / 2.68$ & 2.23 & 0.20 \\
\hline SD Abitur grades & $0.14 / 0.85$ & 0.61 & 0.03 \\
\hline \multicolumn{4}{|l|}{$\begin{array}{l}\text { Job characteristics of first significant job } \\
\text { Part-time job }\end{array}$} \\
\hline Yes & $0 / 1$ & 84.28 & - \\
\hline No & $0 / 1$ & 15.72 & - \\
\hline \multicolumn{4}{|l|}{ Fixed-term contract } \\
\hline Yes & $0 / 1$ & 66.22 & - \\
\hline No & $0 / 1$ & 33.77 & - \\
\hline \multicolumn{4}{|l|}{ Firm size } \\
\hline Large (more than 1000 employees) & $0 / 1$ & 71.82 & - \\
\hline Small (less than 1000 employees) & $0 / 1$ & 28.18 & - \\
\hline \multicolumn{4}{|l|}{ Employment sector } \\
\hline Private manufacturing & $0 / 1$ & 27.00 & - \\
\hline Private service & $0 / 1$ & 34.81 & - \\
\hline Civil service & $0 / 1$ & 38.19 & - \\
\hline Task specificity (occupational level) & $0.17 / 0.67$ & 0.43 & 0.06 \\
\hline \multicolumn{4}{|l|}{ Individual controls } \\
\hline Male & $0 / 1$ & 56.49 & - \\
\hline Female & $0 / 1$ & 43.51 & - \\
\hline Age at graduation & $21 / 51$ & 27.02 & 3.03 \\
\hline
\end{tabular}




\begin{tabular}{|c|c|c|c|}
\hline \multicolumn{4}{|l|}{ Child at graduation } \\
\hline Yes & $0 / 1$ & 8.46 & - \\
\hline No & $0 / 1$ & 91.54 & - \\
\hline \multicolumn{4}{|l|}{ Educational Background } \\
\hline At least one parent with tertiary degree & $0 / 1$ & 47.67 & - \\
\hline No parent with tertiary degree & $0 / 1$ & 52.33 & - \\
\hline Final grade & $1.0 / 4.0$ & 2.03 & 0.65 \\
\hline Duration of study (in months) & $5 / 37$ & 11.26 & 2.86 \\
\hline \multicolumn{4}{|l|}{ Vocational training } \\
\hline Before Abitur & $0 / 1$ & $22 . .52$ & - \\
\hline After Abitur & $0 / 1$ & 14.81 & - \\
\hline No & $0 / 1$ & 62.67 & - \\
\hline \multicolumn{4}{|l|}{ Labour market experience before studies } \\
\hline Yes & $0 / 1$ & 37.55 & - \\
\hline No & $0 / 1$ & 62.45 & - \\
\hline \multicolumn{4}{|l|}{ Field-related jobbing during studies ${ }^{2}$} \\
\hline Yes & $0 / 1$ & 64.65 & - \\
\hline No & $0 / 1$ & 35.35 & - \\
\hline \multicolumn{4}{|l|}{ Mandatory internship during studies } \\
\hline Yes & $0 / 1$ & 72.17 & - \\
\hline No & $0 / 1$ & 27.83 & - \\
\hline
\end{tabular}

Note: Apart from the dependent variables overeducation, job mismatch and the job characteristics the descriptive statistics refer to the first sample on job search duration $(\mathrm{N}=4951) ;{ }^{1}$ As to a potential problem of multicollinearity: A test model that includes the different measures of specificity reveals that the square root of the variance inflation factor (VIF), indicating the impact of collinearity on the precision of the estimates, is clearly under the value of 2 for all three measures. This shows that the multiple correlation between these measures is not large enough to seriously degrade the precision of estimation (Fox 1997, 337). ${ }^{2}$ This variable indicates whether graduates had jobs during their studies that are related to their studies. 